\title{
NATURALEZA Y ALCANCE DE LA PERSONALIDAD JURÍDICA DE LA UNIÓN EUROPEA EN EL ÁMBITO DE LA COOPERACIÓN INTERNACIONAL
}

\author{
JOSÉ A. GIRÓN LARRUCEA \\ Profesor Titular de Derecho Internacional Público de la Universidad de Sevilla
}

\section{SUMARIO}

Introducción.

1. El carácter de tratado internacional multilateral de la constitución Europea.

2. La naturaleza de las competencias atribuidas a las instituciones de la Unión Europea. Principios en que se funda.

3. Alcance de las competencias que podrán ejercer las instituciones de la Unión en materia de acción exterior.

4. La concreción de objetivos de política exterior en la Constitución Europea como elemento de desarrollo de la personalidad jurídica internacional de la Unión. La regulación de los distintos tipos de cooperación.

\section{INTRODUCCIÓN}

El artículo 6 de la Constitución Europea (que reproduce el art. $281 \mathrm{CE}$ ), atribuye a la Unión, de forma general y para todas aquellas materias respecto de las que esté dotada de competencias, una personalidad jurídica única, que se expresará de diferente manera por razón de la materia en la que tenga que actuar, pero no por disfunciones resultantes de que las distintas materias se encuentren reguladas en tratados de distinta naturaleza.

En este sentido, se materializa la desaparición de la estructura de los tres pilares, que constituía una fuente de confusión y de superposición de competencias. Por lo tanto, se establece una única estructura para las instituciones de la Unión, sea cual sea su ámbito de actuación, variando únicamente los procedimientos que se deban utilizar, en función de los caracteres específicos de las materias que se deban reglamentar, de acuerdo con el apartado 4 del art. 3, que fija como objetivos de la Unión que «en sus relaciones con el resto del mundo, la Unión afirmará y promoverá sus valores e intereses. Contribuirá a la paz, la seguridad, el desarrollo sostenible del planeta, la solidaridad y el respeto mutuo entre los pueblos, el comercio libre y equitativo, la 


\section{EL CARÁCTER DE TRATADO INTERNACIONAL MULTILATERAL DE LA CONSTITUCIÓN EUROPEA}

A pesar de su denominación y del intento de acercamiento a la ciudadanía europea, la Constitución sigue siendo una norma internacional convencional. No se ha producido un cambio cualitativo en relación con los tratados todavía vigentes. Su consideración como constitución es solamente analógica, para poner de manifiesto que su función como tratado constitutivo se entiende, en última instancia, que va más allá de la creación de una organización internacional ${ }^{1}$.

Sin embargo, la condición de tratado de la norma fundamental lleva aparejados unos efectos insoslayables, tanto de carácter formal como material.

El sistema del ordenamiento jurídico internacional se distingue porque los sujetos originarios no sólo son los titulares de la soberanía sino que también retienen el ejercicio de la misma. En este sentido, no proceden a delegarla en instituciones que puedan ejercerla de una manera general, como los órganos constitucionales en los sistemas jurídicos internos de los Estados, razón por la cual, desde el punto de vista político, su legitimidad no es directa, sino que se encuentra canalizada a través de los Estados miembros. Asimismo, la enmienda o la modificación de la norma convencional creada también será administrada por ellos directamente y de forma discrecional, y únicamente tendrá validez cuando hayan expresado su consentimiento a estar vinculados por ella, de acuerdo con los sistemas establecidos en sus respectivas constituciones ${ }^{2}$.

De igual manera, cuando atribuyen competencias a una entidad por ellos creada, como pueda serlo la Unión europea, lo hacen de una manera parcial, específica y expresa, referida a la gestión y consecución de los objetivos comunes en ella establecidos y limitada a las materias reguladas en el ámbito del tratado en cuestión, de acuerdo con el principio de derecho internacional de que la limitación, renuncia o delegación de la soberanía nunca se presume, no puede ser implícita ni deducida, sino que tiene que ser claramente y expresamente realizada, preferentemente en acto formal y escrito, en el que quede establecida.

En este sentido, el sistema de elección del Parlamento Europeo no tiene como efecto que esta institución se pueda comparar a los órganos constitucionales que en el sistema jurídico interno de los Estados tienen conferida la función de representación de la ciudadanía y la delegación del ejercicio de la soberanía.

Por el contrario, el Parlamento Europeo es un órgano de una organización internacional en cuyo procedimiento de elección se incluye la participación de los ciudadanos europeos, pero no en su cualidad de titulares de la soberanía del conjunto de los Estados de la Unión. Esta es una característica que se reservan los Estados. Ellos son el poder constituyente y los que disponen de las competencias soberanas de la Unión. La ciudadanía europea no es más que un elemento sustancial del procedimiento establecido para la elección del Parlamento Europeo que, todo lo más, tiene la función de representación pero, tal y como está concebida la estructura del sistema de integración que establece la Constitución, no dispone de la delegación del ejercicio de esa soberanía, ni siquiera en relación con las materias reguladas en el ámbito del tratado.

Bien es verdad que en el actual proyecto de Constitución la función del Parlamento dentro del sistema de integración se refuerza. El procedimiento de codecisión se generaliza. En el sistema todavía vigente en el TCE se utiliza para adoptar decisiones en 37 ámbitos de compe- 
erradicación de la pobreza y la protección de los derechos humanos, especialmente los derechos del niño, la estricta observancia y el desarrollo del Derecho Internacional, y en particular al respeto a los principios de la Carta de las Naciones Unidas».

Ahora bien, teniendo en cuenta la experiencia de la acción comunitaria y la jurisprudencia del TJCE en relación con la actuación de las instituciones de la Unión, la naturaleza y el alcance de la subjetividad jurídica internacional de la Unión hay que ponerla, sobre todo, en relación con la tercera parte de la Constitución, que recoge las disposiciones relativas a las políticas de la Unión. Es la parte funcional referida a los aspectos más clásicos del sistema de integración que anteriormente se establecía en el TCE. En ella se prevé la regulación del funcionamiento del mercado interior y de todas aquellas materias concernientes a la Política Comercial Común en su vertiente internacional, así como las relaciones con el sistema de la OMC.

En este sentido, desde un punto de vista jurídico-constitucional, es muy importante el reconocimiento de la doble naturaleza del sistema de funcionamiento de las instituciones al establecer en el art. 1 que:

»La presente constitución, que nace de la voluntad de los ciudadanos y de los Estados de Europa de construir un futuro común, crea la Unión Europea, a la que los Estados miembros confieren competencias para alcanzar sus objetivos comunes. La Unión coordinará las politicas de los Estados miembros encaminadas a lograr dichos objetivos y ejercerá, de modo comunitario, las competencias que éstos le transfieran».

El desarrollo específico de esta doble naturaleza de competencias se sigue estableciendo en el triángulo institucional básico mantenido desde los tratados fundacionales de los años cincuenta. La Constitución trata de renovar y reforzar cada uno de ellos sin romper su equilibrio institucional y conservando la naturaleza funcional de órganos internacionales que se les confirió desde el principio.

Por otra parte, el mantenimiento del principio de equilibrio institucional como elemento fundamental sobre el que se basa el funcionamiento de este triángulo institucional básico y la naturaleza de las competencias que se atribuyen a las instituciones de la Unión, suponen la prevalencia del carácter de tratado internacional multilateral de la norma fundamental que se establece y el de organización internacional de integración de la Unión frente a cualquier otra concepción como estructura político constitucional.

1 Rodríguez Iglesias, G. C., «La constitucionalización de la Unión Europea», Revista de Derecho Comunitario Europeo, n 16, 2003, pgs. 893-894.

2 Rodríguez Iglesias, G.C., op. cit., p.894 


\section{LA NATURALEZA DE LAS COMPETENCIAS ATRIBUIDAS A LAS INSTITUCIONES DE LA UNIÓN EUROPEA. PRINCIPIOS EN QUE SE FUNDAN}

El artículo 1 del Proyecto de Constitución empieza por distinguir las dos clases principales de competencias que las instituciones comunitarias pueden ejercer, de coordinación y de integración. Ambas son específicas. Las de coordinación, delimitadas por los acuerdos de los Estados respecto a las materias a coordinar. Las correspondientes al sistema de integración, nervio operativo del proyecto de Constitución, todavía más especificadas en la Parte III del mismo.

El mantenimiento por parte de los Estados miembros del ejercicio del poder de decisión sobre el tratado, de esa facultad para generar competencias y para determinar a quién y como corresponde su ejercicio, define esencialmente la naturaleza de la Unión y de las competencias atribuidas a sus órganos. Mientras no se produzca una auténtica transferencia de poder soberano a un órgano representativo, adecuado a las características que vaya adquiriendo la Unión pero con capacidad para determinar sus propias competencias, aunque sea en el ámbito definido de forma general en un tratado, para ser depositario de la delegación real del poder constituyente y estar en situación de determinar los contenidos en los que se funde el desarrollo de la convivencia en la sociedad europea, seguirá vigente el esquema básico de organización internacional de integración, cuya dinámica estará en función de los objetivos asignados en su tratado constitutivo.

Respecto a los principios que las fundamentan, la Constitución Europea resulta mucho más clara y sistemática que los anteriores Tratados constitutivos al introducir un Título III «De las competencias de la Unión», cuyo artículo 9 establece los principios que las fundamentan:

«1. La delimitación de las competencias de la Unión se rige por el principio de atribución. El ejercicio de las competencias de la Unión se rige por los principios de subsidiariedad y de proporcionalidad.»

\subsection{EL PRINCIPIO DE ATRIBUCIÓN}

En su apartado 2, el citado art. 9 dispone:

«2. En virtud del principio de atribución, la Unión actúa dentro de los limites de las competencias que le atribuyen los Estados miembros en la Constitución, con el fin de lograr los objetivos que ésta determinan. Toda competencia no atribuida a la Unión en la Constitución corresponde a los Estados miembross.

El profesor J.-V. Louis estima que la preferencia por el concepto de atribución frente al de transferencia se justifica por el hecho de que las competencias de las instituciones de la Unión no son exacta reproducción de las que ejercen los Estados ${ }^{4}$. Por otra parte, como ya se ha señalado anteriormente, estas instituciones no son constitucionalmente soberanas, sino que únicamente pueden actuar en el ámbito del tratado que las instituye, que no les da un margen para hacerlo del mismo modo que los órganos constitucionales de los Estados 
tencias. Este número en el Proyecto se aumenta hasta 80, de forma que todas las competencias que se ejerzan respecto de las políticas más importantes de la Unión estarán regidas por este procedimiento.

Las materias que se sustraen a esta norma no son más de 12, algunas de los cuales se refieren a competencias con ámbitos de naturaleza constitucional (por ejemplo, cuestiones de ciudadanía europea), y otros constituyen elementos problemáticos para determinados Estados (fiscalidad, algunas cuestiones de política social o de medio ambiente). Pero en ningún caso se le otorgan competencias de carácter general ni el poder para renovarlas directamente, sino que las que se le atribuyen se encuentran especificadas en las normas del tratado.

Esta es una diferencia importante entre el sistema de la norma convencional y el de los sistemas constitucionales internos de los Estados miembros.

En estos últimos se fija una estructura institucional para la acción política y legislativa y unas reglas del juego que hay que respetar. Pero como se tiene en cuenta que esa estructura institucional representa e incorpora la delegación del ejercicio de la soberanía por parte de la ciudadanía, que es su titular, se deja un amplísimo margen de actuación a las instituciones para que se ocupen con total libertad de acción, sólo limitada por los procedimientos establecidos, de cualquier situación que tenga lugar en la sociedad y que deba ser regulada o respecto de la que se deba adoptar una decisión.

Las respectivas constituciones de los Estados definen la naturaleza del ejercicio de las competencias que cada poder puede realizar. Pero los órganos del Estado, sobre todo los que tienen encomendadas las funciones legislativas y ejecutivas, no tienen limitación alguna para dar respuesta a cualquier tipo de situación que genere la sociedad y respecto de la cual tengan que actuar. Sus competencias en este sentido son de carácter originario y general. En el marco de la Constitución de cada Estado y de acuerdo con los principios que esta disponga, pueden generar, modificar o restringir por ellos mismos las competencias que tienen asignadas de forma casi ilimitadamente discrecional.

En cambio, en un tratado constitutivo de una organización internacional se delimitan perfectamente las competencias que los órganos pueden ejercer. Estos se encuentran con su poder de actuación limitado a aquellas competencias necesarias para la consecución de los objetivos establecidos en el tratado por los Estados miembros y no podrán modificarlas en ningún sentido por ellos mismos. Se necesitará la actuación de los Estados a través del procedimiento de revisión establecido en el propio tratado para introducir cualquier enmienda en ellas, aunque también es verdad que una vez que las competencias han sido atribuidas a las instituciones, en este caso de la UE, la atribución tiene carácter definitivo, en tanto en cuanto el tratado permanezca en vigor. Como declaraba el TJCE en la sentencia Costa - ENEL de 15.7.64³ «la transferencia realizada por los Estados desde su orden jurídico interno en beneficio del orden jurídico comunitario de derechos y obligaciones correspondientes a las disposiciones del Tratado, supone una limitación definitiva de sus derechos soberanos, contra lo que no podría prevalecer un acto unilateral ulterior incompatible con la noción de Comunidad (obviamente, en 1964 el TJCE se refería a la CEE)». Es decir, en la medida en que los Estados miembros atribuyen a la Unión en la Constitución competencias en un ámbito determinado, no pueden adoptar unilateralmente medidas que modifiquen su alcance o alteren su significado. 
los creadores y la principal parte interesada en la actividad de la Unión, sino que también se constituyen como agentes y órganos de la misma. Por eso es obligatorio aprovechar y utilizar sus posibilidades de actuación al servicio de los fines de la Constitución y organizar su estructuración dentro del sistema, respecto del que tienen la obligación, según el apartado 2 del art. 5 que dispone que, en virtud del principio de leal cooperación, «la Unión y los Estados miembros se respetarán y asistirán mutuamente en el cumplimiento de las misiones derivadas de la Constitución» y que «los Estados miembros facilitarán a la Unión el cumplimiento de su misión y se abstendrán de todas aquellas medidas que puedan poner en peligro la realización de los fines enunciados en la Constitución»

\subsection{EL PRINCIPIO DE PROPORCIONALIDAD}

El apartado 4 del art. 9 de la Constitución Europea establece que «en virtud del principio de proporcionalidad, el contenido y la forma de la acción de la Unión no excederán de lo necesario para alcanzar los objetivos de la Constitución».

Si el principio de subsidiariedad constituía una limitación en cuanto al ámbito de ejercicio de las competencias de la Unión por razón de la eficacia, el principio de proporcionalidad a su vez limita la acción de las instituciones porque en la adopción de sus actos hay que verificar si los medios que se ponen en práctica son los estrictamente adecuados para la realización del objetivo pretendido o si van más allá de lo que sea necesario para su consecución. En este sentido, el TJCE ya consideraba en la sentencia Rau, de 11.3.87 que «ninguna acción de la Comunidad excederá de lo necesario para alcanzar los objetivos del presente Tratado» ${ }^{6}$.

Ahora bien, como señala el AG Léger en sus conclusiones en el asunto Reino UnidoConsejo de 12.3.96 ${ }^{7}$, el principio de proporcionalidad se distingue del principio de subsidiariedad en que este último implica que (entonces) la CE, en adelante la Unión, sólo intervendrá en los ámbitos de competencias compartidas en la medida en que los objetivos de la actuación propuesta no puedan ser alcanzados de manera suficiente por los Estados miembros y, por consiguiente, puedan cumplimentarse mejor a nivel comunitario, haciendo referencia a sectores completos de actividad. En cambio, el principio de proporcionalidad se refiere a los actos concretos que puedan adoptar las instituciones de la Unión que, al determinar su contenido, deben procurar que no exceda de lo necesario para alcanzar el objetivo propuesto, estableciendo así un criterio de economía de medios para mantener la actuación comunitaria en los límites de lo imprescindible para obtener un resultado eficaz. Se trata de evitar una tendencia intervencionista, manteniendo siempre la eficacia suficiente para la realización de los objetivos de la Unión.

Hay que tener en cuenta que estos dos principios se aplican sucesivamente en dos niveles diferentes de la acción de las instituciones de la Unión. El principio de subsidiariedad condiciona la puesta en marcha de la actuación institucional, aplicándose a la definición del ejercicio de su competencia en un determinado sector de actividad. Sin embargo, una vez que se ha establecido que la actuación comunitaria en ese sector es adecuada, hay que aplicar el principio de proporcionalidad al determinar la naturaleza, el alcance y el conteni-

4 Louis, J.-V., El ordenamiento jurídico comunitario, $5^{\text {a }}$ ed., 1995, p. 19

5 Bol. CE, 10-92 
miembros. Como ya se ha apuntado, estas competencias se atribuyen en función de los objetivos que los Estados miembros han fijado en la Constitución como elementos esenciales de la acción de la Unión y las instituciones no pueden alterar ni modificar ni uas ni otros, sino que en caso de que se estime necesario, tendrían que ser los Estados, actuando como tales (no como elementos componentes de la Unión), quienes deberían proceder a realizarlo a través de la CIG, de acuerdo con el procedimiento de revisión establecido en la propia Constitución.

\subsection{EL PRINCIPIO DE SUBSIDIARIEDAD}

El apartado 3 del art. 9 establece que «en virtud del principio de subsidiariedad, en los ámbitos que no sean de su competencia exclusiva la Unión intervendrá sólo en la medida en que los objetivos de la acción pretendida no puedan ser alcanzados de manera suficiente por los Estados miembros bien a nivel central o bien a nivel regional y local, sino que puedan alcanzarse mejor debido a la dimensión o a los efectos de la acción contemplada, a nivel de la Unión».

Aunque establecido por primera vez de manera expresa por el Tratado de Maästricht en el art. 3 b CE (art. 5 CE del Tratado de Amsterdam), este principio procede de la actuación de la propia estructura institucional y de la jurisprudencia del TJCE, a través del análisis de elementos que se han ido configurando en la práctica de una organización internacional de integración como la CE.

Por su parte, la Comisión en su comunicación al Consejo y al Parlamento Europeo de $27.10 .92^{5}$, realizaba una interpretación totalmente funcional del antiguo art. $3 \mathrm{~b}$, tratando de analizar con la mayor claridad posible todos los aspectos del principio.

En este sentido, la Comisión entiende que el principio de subsidiariedad impone una obligación específica a las instituciones que participen en el proceso de decisión consistente en que la CE antes, ahora la Unión, en el ejercicio de sus competencias no debe hacer más de lo que su funcionamiento pueda asegurar mejor a nivel comunitario.

Por eso se considera como un elemento de legalidad de sus actos la obligación de incluir en la motivación de los mismos la justificación de la necesidad de que sean ellas quienes legislen y actúen a nivel comunitario. Aunque las competencias de la Unión se determinan de acuerdo con el principio de atribución, su ejercicio se regula según los principios de subsidiariedad y de proporcionalidad.

Por otra parte, el análisis del carácter de una decisión de las instituciones, de acuerdo con el principio de subsidiariedad, no puede disociarse de su contenido, entre otras cosas porque por el principio de especialidad cada materia regulada en la Constitución está identificada con su adopción mediante un determinado procedimiento.

Así concebido, el principio de subsidiariedad constituye un elemento estructurador de la actuación de la Unión. No se trata de obstaculizar ni de limitar las funciones de las instituciones, sino que se pretende regular su desarrollo para que esté plenamente justificado.

En el fondo se está definiendo la naturaleza funcional de la Unión. Su instauración no supone que los objetivos que se le atribuyen tengan que conseguirse únicamente mediante la actuación de las instituciones de su sistema orgánico. La creación de una organización que integra a los Estados miembros no es lo más importante. Lo que importa verdaderamente es cumplir los objetivos de la Constitución y, en ese sentido, los Estados no sólo son 


\section{EL ALCANCE DE LAS COMPETENCIAS QUE PODRÁ EJERCER LA UNIÓN EUROPEA EN MATERIA DE ACCIÓN EXTERIOR}

En el análisis de los ámbitos de actuación en esta materia resulta difícil, al menos por el momento, ir más allá de los que han realizado la profesora Paz de Andrés, en cuanto se refiere a las relaciones entre la Comunidad Europea y las Organizaciones Internacionales? y la profesora Petit Gabriel, respecto a la regulación general del despliegue de la personalidad jurídica internacional de la Unión Europea en la Constitución Europea ${ }^{10}$.

Sin embargo si que existe un elemento de investigación en cuanto al criterio que se va a utilizar para determinar el alcance del ejercicio de las competencias específicas, por cuanto parece que se han introducido algunas variantes en la concepción que se mantenía hasta ahora respecto a la extensión y automaticidad del desarrollo de la competencias implícitas por parte de las instituciones comunitarias, siempre que fuese necesario para hacer efectiva la regulación de sectores de actividad cubiertos por el Tratado, en el futuro por la Constitución

Así, respecto de la competencia para celebrar acuerdos internacionales, el apartado 1 del art. III-225 establece que «la Unión podrá celebrar acuerdos con uno o varios terceros Estados u organizaciones internacionales cuando la Constitución así lo prevea o cuando la celebración de un acuerdo sea necesaria para alcanzar, en el contexto de las políticas de la Unión, alguno de los objetivos establecidos por la Constitución, esté prevista en un acto jurídico vinculante de la Unión o afecte a un acto interno de la Unión».

Este artículo parece incorporar la jurisprudencia establecida por el tribunal desde la sentencia AETC, de 31.3.7111.

\subsection{LA INTRODUCCIÓN POR EL TJCE DE UN CRITERIO CORRECTOR DE LA AUTOMATICIDAD DE LA EXISTENCIA DE UNA COMPETENCIA EXCLUSIVA EN LA ACCION EXTERIOR COMO CONSECUENCIA DEL EFECTO ÚTIL DE UNA COMPETENCIA INTERNA}

La tendencia a considerar que la existencia de normas comunes reguladoras de una actividad comprendida en el ámbito de una política común, no solo proporcionaba automáticamente a las instituciones comunitarias competencia para celebrar acuerdos internacionales cuando fuera necesario para completar la eficacia de las normas internas, sino que esa competencia también resultaba exclusiva aunque no estuviera expresamente establecido en el Tratado, parecía haber adquirido carta de naturaleza en la dinámica de la acción exterior de la CE desde la citada sentencia AETC, consolidada en reiterada Jurisprudencia.

Sin embargo, el TJCE en las «Sentencias Cielos Abiertos» de 5.11.2002 ${ }^{12}$, aunque acepta la extensión de las competencias de las instituciones internas de las instituciones a

6 TJCE, Rec. 1987 , p. 1069

7 TJCE, Rec. 1996, p. I-5783

8 Strozzi, G., Le principe de subsidiarieté dans la perspective de l'integration européenne, RTDE, 1994, p. 379. 
do del acto.. Incide en una acción ya emprendida y tiene por objeto su adecuación estricta a la realización de los objetivos de la Unión. El principio de subsidiariedad habría intervenido en un momento anterior, es decir, al decidir si el acto se adopta o no por las instituciones de la Unión ${ }^{8}$.

\subsection{EL PRINCIPIO DE ESPECIALIDAD}

El apartado 6 del art. 11 de la Constitución Europea establece que «el alcance y las condiciones de ejercicio de las competencias de la Unión se determinarán en las disposiciones especificas de cada ámbito contenidas en la Parte III». Es decir, que para la determinación del alcance específico de las actuaciones de las instituciones de la Unión, la Constitución reenvía a lo que dispone en su parte más funcional, allí donde se articulan en cada disposición los contenidos precisos de cada materia y los procedimientos mediante los que las instituciones podrán adoptar decisiones para su regulación.

De esta forma se considera que el funcionamiento de la Unión debe ser el correspondiente a una organización de naturaleza funcional, y este principio es inherente a una organización de este tipo, cuyas competencias le han sido atribuidas para la realización de los objetivos cuya consecución se le asigna en el tratado constitutivo. Constituye un fundamento esencial para la adopción de los actos de sus instituciones y, al mismo tiempo, un límite más allá del cual dichos actos quedarían desprovistos de efectos jurídicos y, por lo tanto, serían nulos de pleno derecho.

El fundamento de este principio reside en el hecho que la atribución de competencias que se lleva a cabo en la Constitución Europea y que, entre otras cosas, implica la posibilidad de que unas instituciones internacionales puedan adoptar actos obligatorios para los Estados miembros, supone una limitación de las competencias soberanas propias de dichos Estados. Por eso hay que establecer de forma concreta y determinada que competencias se atribuyen, puesto que las limitaciones de la soberanía de los Estados nunca se presume, sino que tiene que ser expresa y claramente establecida y aceptada. Esa es la razón de que en la Constitución , al lado de normas de carácter general, se encuentren otras disposiciones que en los sistemas jurídicos internos de los Estados miembros no tendrían otro rango que el de reserva de ley. Sin embargo, en una norma internacional convencional, que constituye una organización internacional de integración, esta especificidad es necesaria para dar lugar a la suficiente seguridad jurídica como para que los Estados miembros no mantengan reservas frente a sus actos unilaterales y actúen en el marco del principio de la buena fe, absolutamente necesario para el desarrollo de un proyecto como el que han incorporado los Tratados constitutivos y, a partir del momento en que entre en vigor, la Constitución Europea.

9 De Andrés y Sáenz de Santamaría, P., La Unión Europea en el concierto de las Organizaciones Internacionales, Revista de Derecho de la Unión Europea, n 3, $2^{\circ}$ trimestre 2002, pgs. 121 a 142

10 Petit de Gabriel, E. W., La Unión Europea tras el Proyecto de Constitución ¿la definición formal de un actor o el nacimiento de un diseño coherente de la acción exterior?, Anuario de Derecho Europeo, n 3, 2004, pgs. 47 a 85 
en vigor el acuerdo internacional. En este sentido, la competencia para celebrar acuerdos con terceros Estados deriva, en cualquier caso, de manera implícita de las disposiciones del TCE que establezcan la competencia interna, por lo que la participación de la CE en el acuerdo internacional es necesaria para la realización de los objetivos del TCE.

Por lo tanto, del análisis que efectúa el TJCE en este dictamen se podían extraer dos elementos básicos para la existencia de la competencia externa de la CE:

a) que el TCE confiera explícitamente competencias a las instituciones en el ámbito interno para la consecución de un objetivo determinado;

b) aun cuando las competencias internas no se puedan ejercer más que en el caso en que se celebre y entre en vigor un acuerdo internacional, la CE tendrá competencia externa para celebrar dicho acuerdo, siempre que sea necesario para la consecución de los objetivos del TCE.

B) La pretensión de la Comisión de que esta competencia externa de la CE además fuera exclusiva

Sobre la base de este dictamen, cuyo sentido fue aclarado por los dictámenes 1/94, de 15.11.94 ${ }^{16}$ y 2/92, de 24.3.95 ${ }^{17}$, y de la sentencia AETC, la Comisión pretendía fundamentar la existencia de una competencia exclusiva de la CE para celebrar un acuerdo internacional aun cuando no haya disposiciones comunitarias en el ámbito de que se trate, siempre que la celebración de dicho acuerdo sea necesaria para realizar objetivos del TCE en el referido ámbito y no sea posible alcanzar dichos objetivos mediante la mera adopción de normas comunes autónomas.

C)La apreciación del TJCE sobre la supuesta existencia de una competencia externa exclusiva de la CE en el sentido del dictamen 1/76

El TJCE empieza por señalar que , en materia de transporte aéreo, el apartado 2 del art. 84 (80 actual) se limita a prever una facultad de actuación de la CE que supedita, no obstante, a una decisión previa del Consejo, entendiendo por tanto que, si bien este artículo puede ser utilizado por el Consejo como fundamento jurídico para reconocer a la CE la facultad de celebrar un acuerdo internacional en materia de transporte aéreo en un caso determinado, no se puede considerar que establezca por sí sola una competencia comunitaria externa en materia de transporte aéreo.

Por supuesto, el TJCE en el citado dictamen 1/76 ha interpretado que la competencia de la CE para contraer obligaciones internacionales no sólo resulta de una atribución expresa del TCE, sino que también puede derivarse de manera implícita de las disposiciones de éste. Tal competencia implícita existe tanto en el caso en que se haya ejercido la competencia interna para adoptar medidas relativas a las políticas comunes como cuando

11 TJCE, sentencia Comisión/Consejo, asunto 22/70, Rec 1971, p. 263

12 Sentencias Comisión/Dinamarca, C-467/98 (Rec. 2002, p. I-955); Comisión/ Suecia, C-468/98 (Rec. 2002, p. I-9575); Comisión/Finlandia, C-469/98 (Rec. 2002, p. I-9627); Comisión/Bélgica, C-471/98 (Rec. 2002, p. I-9681); Comisión/Luxemburgo, C-472/98 (Rec. 2002, p. I-9741); Comisión/Austria, C-475/98 (Rec. 2002, p. I-9797); Comisión/alemania, C-476/98 (Rec.2002, p. I-9855). 
la celebración de acuerdos internacionales cuando sea necesario para completar su eficacia, se separa de su anterior jurisprudencia y no considera que además de necesaria esta extensión sea también exclusiva.

La Comisión había considerado que los acuerdos bilaterales de «cielo abierto» celebrados entre los Estados Unidos y algunos de los Estados miembros de la CE, además de suponer un incumplimiento resultante de una infracción de los artículos 5 (10 actual) y 52 (43 actual) TCE y de los Reglamentos 2407/92 y 2299/89, constituían una invasión de la competencia externa de la CE al contraer las obligaciones controvertidas. A este respecto entendía que esta competencia resulta de forma implícita, por una parte, de la necesidad de celebrar a nivel comunitario un acuerdo que contenga tales obligaciones, en el sentido del dictamen $1 / 76$ de $26.4 .77^{13}$ y, por otra parte, del hecho de que dichas obligaciones afectan a las normas adoptadas por la CE en materia de transporte aéreo, tal y como se interpretan en la sentencia AETC de 31.3.71'14.

A) La competencia implícita externa de la CE en el sentido del dictamen 1/76

El TJCE había declarado en este dictamen, de una manera más nítida todavía que posteriormente en la sentencia Kramer (Comisión/Reino Unido) de 5.5.81'15, que la CE podía ejercer directamente en el ámbito externo una competencia interna atribuida por el Tratado cuando su ejercicio en el ámbito interno no fuera suficiente para la consecución de alguno de sus objetivos.

En este sentido, el Tribunal entiende que la base para que la CE participe en la celebración de un acuerdo internacional debe ser la necesidad de ejercer esa competencia también en el ámbito externo para que la competencia que tiene específicamente atribuida en el interno alcance toda la eficacia que sea imprescindible (efecto necesario) para la consecución de los objetivos del TCE, constituyendo el concepto de necesidad el fundamento y el límite de la competencia comunitaria.

De esta forma, el TJCE entendía que la competencia para aceptar compromisos internacionales podía resultar no sólo de una atribución explícita por el TCE sino también derivar de forma implícita de sus disposiciones. Siempre que el derecho comunitario haya conferido a las instituciones competencias en el ámbito interno para la consecución de un objetivo determinado, la CE tendrá asimismo competencia para aceptar los compromisos internacionales necesarios para la realización de este objetivo, incluso en ausencia de una disposición expresa a este respecto.

El TJCE considera que, aunque esta conclusión se impone en particular en todos los casos en que ya se haya ejercido la competencia interna adoptando medidas para la realización de las políticas comunes, esta posibilidad no queda limitada a este supuesto aun cuando las medidas comunitarias no vayan a ser adoptadas más que en el caso en que se celebre y entre

13 TJCE, Rec. 1977 , p. 741

14 TJCE, Rec. 1971, p. 263

15 TJCE, Rec. 1981, p. 1045. En ella el TJCE considera que en materia de protección de recursos marinos no existían en el Tratado disposiciones que autorizasen expresamente a la CE a celebrar acuerdos internacionales, por lo que había que fundamentarse en su capacidad general de actuación externa para encontrar fundamento al desarrollo de una competencia necesaria para la consecución de los objetivos del TCE. 
competencias implícitas dentro del sistema del derecho comunitario partiendo de la subjetividad jurídica internacional de la entonces CEE, que la habilitaba para establecer vínculos contractuales con terceros Estados en relación con la consecución de los objetivos del Tratado. En este sentido, el TJCE considera que esta competencia no sólo resulta de la atribución explícita que se haga en las disposiciones del TCE, sino que puede derivarse de las mismas y de actos de derecho derivado, para que alcancen toda la eficacia que es precisa para la consecución de los objetivos de la CE (efecto útil).

De esta forma, interpreta que siempre que las instituciones CE ejerzan una competencia a través de la adopción de normas comunes, los Estados miembros, ya actúen individual o colectivamente, perderán la facultad de celebrar acuerdos con terceros Estados que puedan afectar el cumplimiento de esas normas. Así pues, en la aplicación de las disposiciones del TCE, no se puede separar el régimen aplicable al cumplimiento de las medidas internas de la CE del ejercicio de las competencias correspondientes en las relaciones exteriores y los Estados miembros, de acuerdo con el art. 5 (art. 10 actual), deben, por un lado, adoptar todas las medidas apropiadas para asegurar el cumplimiento de las obligaciones derivadas del TCE o resultantes de los actos de las instituciones y, por otro lado, abstenerse de realizar cualquier tipo de acto que pueda perjudicar la realización de los objetivos del TCE.

E) La apreciación restrictiva del TJCE sobre la existencia de una supuesta competencia externa exclusiva de la CE en el sentido de la sentencia AETC

El TJCE, en la sentencia AETC, había abierto de forma contundente una línea de interpretación extensiva del concepto de competencia externa y exclusiva de la CE que en estas sentencias, especialmente en la apreciación de esta alegación de la Comisión, parece reconsiderar. Hay que recordar que en sus razonamientos de 1971, el TJCE estimaba que «dado que el art. 75 del Tratado confiere a la Comunidad una competencia definida en términos amplios con el fin de poner en práctica la política común de transportes, dicho artículo debe aplicarse tanto a las relaciones exteriores como a las medidas internas en la materia de que se trate, que el efecto útil de esta disposición se vería menoscabado si las facultades que prevé y, especialmente, la de establecer «cualquier disposición oportuna», en el sentido de la letra c) del apartado 1 del citado artículo, no debieran extenderse a la celebración de acuerdos con Estados terceros. Que si bien, originariamente esta competencia no abarca la totalidad del ámbito de los transportes, no obstante tiende, según la Comisión, a hacerse general y exclusiva a medida que se aplica la política común en este sector.

"Considerando que, a falta de disposiciones especificas del Tratado relativas a la negociación y a la conclusión de acuerdos internacionales en el ámbito de la política de transportes - categoría a la que básicamente corresponde el AETR - procede remitirse al sistema general del derecho comunitario atinente a las relaciones con Estados terceros, que, al objeto de fijar, en un caso determinado, la competencia de la Comunidad para celebrar acuerdos internacionales, debe tomarse en consideración tanto el sistema del Tratado como sus disposiciones materiales, que dicha competencia no sólo es atribuida explícitamente por el Tratado... sino que también puede derivarse de otras disposiciones del Tratado y de actos adoptados, en el marco de estas disposiciones, por las Instituciones de la Comunidad. 
las medidas comunitarias internas no se adopten hasta el momento de entrada en vigor del acuerdo internacional correspondiente, por lo que la competencia de la CE para celebrar acuerdos con terceros Estados puede derivar de forma implícita de las disposiciones del TCE que establecen la competencia interna, siempre que la participación de la CE en el acuerdo sea necesaria para la consecución de los objetivos del TCE.

Ahora bien, en el dictamen 1/94 anteriormente citado, precisó que el supuesto contemplado en el dictamen $1 / 76$ es aquel en que la competencia interna únicamente puede ejercitarse adecuadamente al mismo tiempo que la competencia externa, de modo que la celebración del acuerdo internacional sea necesaria para realizar los objetivos del TCE que no puedan alcanzarse mediante el establecimiento de normas autónomas, circunstancia que no tiene lugar respecto de la materia regulada en el caso de los acuerdos «de cielo abierto». En efecto, en el TCE no hay ninguna disposición que impida a las instituciones organizar acciones concertadas frente a los Estados Unidos ni determinar las actitudes que los Estados miembros deben adoptar frente al exterior, con el fin de paliar las discriminaciones o las distorsiones de la competencia que podrían resultar de la aplicación de los acuerdos «de cielo abierto».

De la numerosa y reiterada jurisprudencia del TJCE en el área de los transportes, se puede concluir que la competencia externa de la CE no se origina ipso facto en su poder para adoptar normas en el ámbito interno. Los Estados miembros no pierden sus competencias para celebrar acuerdos con terceros Estados más que en la medida en que se vayan instaurando normas comunes que puedan resultar afectadas por las obligaciones establecidas en dichos acuerdos. La competencia de la CE se transforma en exclusiva únicamente en la medida en que se adopten normas comunes en el ámbito interno. Ahora bien, no se puede considerar que todas las cuestiones de transporte hayan sido ya reguladas por normas comunes, ni que los Estados miembros hayan perdido todas sus competencias para celebrar acuerdos internacionales en esta materia.

Por otra parte, en el supuesto de que el ejercicio de esta competencia por parte de los Estados miembros implique el riesgo de producir distorsiones de flujo de servicios y de perturbación de la unidad del mercado interior, nada impide a las instituciones CE organizar, mediante las normas comunes que pueden adoptar, acciones concertadas respecto de Estados terceros ni de regular los comportamientos que deben observar los Estados miembros en sus relaciones exteriores en este ámbito.

En este sentido, los capítulos del TCE sobre competencia, derecho de establecimiento y libre prestación de servicios no contienen ninguna disposición que extienda expresamente la competencia de la CE a las relaciones regidas por el Derecho Internacional. Su único objetivo es asegurar la libre competencia, el derecho de establecimiento y la libre prestación de servicios en beneficio de los nacionales de los Estados miembros, sin establecer ningún tipo de disposición referida al problema del primer establecimiento de los nacionales de terceros Estados y al régimen de su acceso a actividades no asalariadas. Por lo tanto no se puede deducir de forma automática de estos capítulos una competencia exclusiva de la CE para celebrar acuerdos con terceros Estados en Estas materias.

D) La competencia implícita externa de las instituciones de acuerdo con la Sentencia AETC

El TJCE en la sentencia AETC aplicaba de manera muy elaborada la teoría de las 
Estados miembros no podrían contraer obligaciones internacionales al margen de las instituciones comunes, aunque no exista ninguna contradicción entre éstas y las normas comunes. Incluso, sigue su razonamiento en la línea de la sentencia AETC y de los dictámenes 1/94 y 2/92 al declarar (por ejemplo, en el apartado 83 de la sentencia Comisión/Dinamarca) que, cuando la Comunidad ha incluido en sus actos legislativos cláusulas relativas al trato que ha de otorgarse a los nacionales de países terceros, o ha conferido expresamente a sus instituciones competencia para negociar con los países terceros, adquiere una competencia externa exclusiva en la medida cubierta por dichos actos, lo mismo que sucede cuando la Comunidad haya llevado a cabo una armonización completa en un ámbito determinado, ya que las normas comunes así adoptadas podrían verse afectadas, en el sentido de la sentencia AETC, si los Estados miembros conservaran libertad de negociación con los países terceros.

Hasta aquí el TJCE no tiene inconveniente en aceptar su propia jurisprudencia establecida (y coherentemente seguida hasta la fecha) en la sentencia AETC. Sin embargo, y de manera que parece forzada, a continuación se separa de ella al contemplar la aplicación de la jurisprudencia citada a la consideración de las normas concretas. En este sentido, su razonamiento discurre de forma distinta a como había resuelto una situación similar en los apartados 23 a 31 de la sentencia $\mathrm{AETC}^{19}$, al declarar en las sentencias «cielos abiertos» ${ }^{20}$ que, de acuerdo con los apartados 78 y 79 del dictamen 1/94, «las eventuales distorsiones en los flujos de servicio en el mercado interior que pueden derivarse de los acuerdos bilaterales denominados «de cielo abierto» celebrados por los Estados miembros con terceros países no afectan por sí mismas a las normas comunes adoptadas en este ámbito $y$, por tanto, no pueden ser fundamento de una competencia externa de la Comunidads. Y que, como considera en el apartado 86 de la sentencia Comisión/Dinamarca, «en efecto, en el Tratado no hay ninguna disposición que impida a las instituciones organizar dentro de las normas comunes que adopten acciones concertadas frente a países terceros, ni determinar las actitudes que los Estados miembros deben adoptar frente al exterior (dictamen 1/94, antes citado, apartado 79)》.

Este criterio del dictamen 1/94, que matiza a la sentencia AETC, sin embargo no es incompatible con ella. No supone lo contrario de lo que la sentencia establece, sino simplemente tiene en cuenta una posibilidad más, la de que las instituciones CE organicen un sistema concertado de actuación externa. Lo que ocurre es que el dictamen 1/94 se adopta para contestar a una serie de preguntas de la Comisión respecto del carácter exclusivo o no de la competencia atribuida a la CE por el art. 113 (133 actual), sobre el paralelismo de las competencias internas y externas en materia de política comercial común o sobre las que le confieren los arts. 100 A (95 actual) o 235 (308 actual), para concluir el Acuerdo general sobre el comercio de servicios y el Acuerdo relativo a los aspectos de los derechos de propiedad intelectual referidos al comercio, que por su propia naturaleza se prestan al tipo de consideración, más amplia y flexible, de las competencias de la CE y de las que los Estados retienen para negociar acuerdos en ese ámbito, siempre que no entren en conflicto con los Tratados o con las normas de derecho derivado.

En cambio, en este aspecto, no hace referencia a los considerandos 23 a 31 de la sentencia AETC, que posiblemente fuesen más directamente aplicables y que previsiblemente condujeran a la apreciación de la pretensión de la Comisión fundada en esta jurisprudencia del propio TJCE.

En este sentido, se puede considerar que el TJCE realiza una interpretación claramente restrictiva de las competencias de la CE para celebrar acuerdos internacionales en los apartados posteriores, en que sigue justificando la desestimación de la pretensión de la Comisión sobre la existencia de una supuesta competencia exclusiva externa en el sentido de la jurisprudencia AETC. 
"Que, en particular, cada vez que la Comunidad, con el fin de aplicar una política común prevista por el Tratado, adopta disposiciones que establecen normas comunes, en la forma que sea, los Estados miembros ya no tienen la facultad, bien actuen individual o incluso colectivamente, de contraer con Estados terceros obligaciones que afecten a dichas normas.

"Que, en efecto, a medida que se establecen estas normas comunes, sólo la Comunidad puede asumir y ejecutar, con efecto para todo el ámbito de aplicación del ordenamiento jurídico comunitario, los compromisos contraídos con Estados terceros».

"Que, por lo tanto, en la aplicación de las disposiciones del Tratado, no se puede separar el régimen de medidas internas de la Comunidad y el de relaciones exteriores.

"Considerando que... conjugando estas disposiciones (letra e) del art. $3 y$ art. 5 TCEE), la consecuencia es que, en la medida en que se adoptan normas comunitarias para realizar los fines del Tratado los Estados miembros no pueden, fuera del marco de las instituciones comunes, contraer compromisos que puedan afectar a dichas normas o alterar su alcance» ${ }^{18}$.

Parece evidente la intención del TJCE de extender de una manera decidida la competencia exclusiva de la Comunidad en materia de transportes a aquellos acuerdos con terceros Estados que se consideren necesarios, por lo menos, para asegurar el efecto útil de la norma al regular de forma completa (tanto en el exterior como en el interior del sistema comunitario) un determinado sector de actividad.

Sin embargo, esta interpretación amplia y finalista que se fundaba ante todo y sobre todo en la consecución de los objetivos del Tratado, parece diluirse en buena parte en la apreciación que hace el TJCE de la alegación de la Comisión, pretendiendo que fundamentase también el incumplimiento de los Estados miembros que habían celebrado los acuerdos en materia de transporte aéreo con Estados Unidos en la infracción del sistema que parecía haberse consolidado a partir de la sentencia AETC.

A este respecto, el TJCE establece una línea de razonamiento que parte de reconocer que en los apartados 16 a 18 y 22 de la sentencia AETC, consideraba que la competencia de la Comunidad para celebrar acuerdos internacionales no sólo es atribuida explícitamente por el Tratado sino que también puede derivarse de los actos adoptados por las instituciones de la Comunidad con el fin de aplicar una política común prevista por el TCE y, por otra parte, que los Estados miembros ya no tienen la facultad de contraer con Estados terceros obligaciones que afecten a dichas normas, por lo que únicamente la Comunidad puede asumir y ejecutar los compromisos contraídos frente a terceros países.

Pero aun así, en el caso de los acuerdos entre Estados miembros de la CE y los Estados Unidos en materia de transporte aéreo, estima el TJCE que aunque el Consejo haya adoptado normas comunes sobre la base del art. 84, apartado 2 del TCE (art. 80.2 actual), es necesario determinar además en que circunstancias puede verse afectado o alterado el alcance de las normas comunes por las obligaciones internacionales consideradas y, por tanto, en qué condiciones adquiere la Comunidad una competencia externa como consecuencia del ejercicio de su competencia interna.

En este sentido cita el apartado 30 de la sentencia AETC para determinar que se da el caso cuando las obligaciones internacionales están comprendidas dentro del ámbito de aplicación de las normas comunes o, de acuerdo con el dictamen 2/91, dentro de un ámbito ya cubierto en gran medida por tales normas. En este caso, El TJCE no tiene inconveniente en aceptar que los 
rio del TJCE en cuanto a la capacidad de ejercicio de sus competencias por parte de las instituciones en materia de acuerdos internacionales, pero sin extender el ámbito de las mismas en el sentido de la pretensión de la Comisión de que, además de tener derecho a ejercerlas, este derecho, cuando actuase la Unión, fuese de naturaleza exclusiva. Al no incluir este aspecto el apartado 1 del art. III-225, se puede entender que el concepto expuesto por el TJCE en las sentencias «cielos abiertos» ha sustituido al que se expresaba en la sentencia AETC como referente jurisprudencial para la interpretación del alcance de la competencia de las instituciones en materia de celebración de acuerdos internacionales.

\section{LA CONCRECIÓN DE OBJETIVOS DE COOPERACIÓN INTERNACIONAL Y LA REGULACIÓN DE LA ACTUACIÓN DE LAUNIÓN EN ESTE ÁMBITO EN LACONSTITUCIÓN EUROPEA COMO ELEMENTO DE DESARROLLO DE LA PERSONALIDAD JURÍDICA INTERNACIONAL DE LA UNIÓN.}

En el ámbito de los objetivos de cooperación asignados a la Unión, la Constitución Europea establece diversos tipos ${ }^{21}$. Por una parte, regula las que se podrían considerar como clásicas (cooperación de carácter económico, financiero o técnico con terceros Estados y la correspondiente con otras Organizaciones Internacionales), pero añade como objetivos propios de la Unión la realización de actuaciones específicas (relaciones de vecindad, cooperación al desarrollo y régimen de asociación) que suponen el ejercicio de competencias cualificadas que, sin duda, contribuirán a proporcionar un contenido sustantivo a la acción exterior de la Unión Europea.

A) Como señala la profesora Petit Gabriel, «una de las grandes novedades del proyecto constitucional en cuanto a la acción exterior de la Unión es elevar al nivel del tratado constitutivo — llámese Constitución — la ayuda humanitaria. Nacida de la práctica, la ayuda bumanitaria no tenía un fundamento propio en los tratados constitutivos. En el proyecto de Constitución recibe su bautismo, siendo considerada una de las competencias compartidas de tipo especial, que permite el ejercicio coetáneo de la competencia por la instancia nacionaly la Unión (artículo 13, apartado cuarto, y artículo III-223, apartado uno, último inciso).

19 TJCE, Rec., Selección de 1971, pgs. 30 y 31. En ellos el Tribunal declara que:

"23. Considerando que, según el art. 74770 actual) los objetivos del Tratado en materia de transportes se persiguen en el marco de una politica común;

"24. que, a tal efecto, el apartado 1 del articulo 75 (71 actual) encarga al Consejo establecer normas comunes y adoptar, además, «cualquier otra disposición oportuna";

"25. que, a tenor de la letra a) de la misma disposición, dichas disposiciones comunes son aplicables «a los transportes internacionales efectuados desde el territorio de un Estado miembro o con destino al mismo o a través del territorio de uno o de varios Estados miembros»;

"26. que esta disposición se refiere también a los transportes procedentes de Estados terceros o con destino a los mismos, en lo que respecta a la parte del trayecto que se efectúa en el territorio comunitario;

"27. que, por tanto, supone que la competencia de la Comunidad se extiende a relaciones que entran en el ámbito del Derecho internacional e implica, por consiguiente, en la esfera de que se trata, la necesidad de acuerdos con los Estados terceros interesados;

"28. que, si bien es cierto que los artículos 74 y 75 no prevén explícitamente a favor de la Comunidad una competencia a favor de la celebración de acuerdos internacionales, la entrada en vigor... del Reglamento (CEE) nº 543/69 del Consejo...produjo necesariamente el efecto de atribuir a la Comunidad la competencia para celebrar con los Estados terceros cualquier acuerdo relativo a la materia regulada por dicho Reglamento;

"30. Considerando que, dado que la materia del AETR está comprendida dentro del ámbito de aplicación del Reglamento $n^{\circ} 543 / 69$, la competencia para negociar y concluir el acuerdo de referencia corresponde a la Comunidad desde la entrada en vigor 
De esta forma, en el apartado 90 de la sentencia Comisión/Reino de Dinamarca, el TJCE considera que «como resulta de su título y de su artículo 3, apartado 1, el Reglamento $n$. 2408/92 se refiere al acceso a las rutas intracomunitarias únicamente de las compañias aéreas comunitarias, que se definen en el artículo 2, letra b) de este Reglamento como toda compañía aérea que posee una licencia de explotación válida expedida por un Estado miembro con arreglo al Reglamento $n$. 2407/92. Según se desprende de sus articulos 1, apartado 1, y 4, este Reglamento define los requisitos para la concesión por parte de los Estados miembros de licencias de explotación a las compañias aéreas establecidas en la Comunidad que, sin perjuicio de los acuerdos y convenios en los que la Comunidad sea parte contratante, sean propiedad, bien directamente o bien mediante participación mayoritaria, de Estados miembros y/o nacionales de Estados miembros y estén efectivamente controladas por dichos Estados o nacionales, así como los criterios de mantenimiento en vigor de las citadas licencias.

«De lo anterior se deduce que el Reglamento n. 2408/92 no regula la concesión de derechos de tráfico en rutas intracomunitarias a las compañias aéreas no comunitarias. Del mismo modo, el Reglamento n. 2407/92 no regula las licencias de explotación de las compañias aéreas no comunitarias que operen dentro de la Comunidad.

"Como las obligaciones internacionales controvertidas no están comprendidas en un ámbito que ya esté cubierto por los Reglamentos n. 2407/92 y 2408/92, no se puede considerar que afecten a estos reglamentos por el motivo invocado por la Comisión.

"Además, el mero becho de que estos dos Reglamentos no regulan la situación de las compañias aéreas de terceros países que operan dentro de la Comunidad demuestra que, al contrario de lo que afirma la Comisión, el «tercer paquete» de la normativa no tiene carácter completo».

Se puede apreciar en esta parte de la sentencia que el TJCE prescinde de todos los elementos que se pueden derivar de forma implícita, aunque también muy directa, de las normas, tanto del Tratado como de derecho derivado, y opta por la exigencia de unas condiciones reforzadas que pongan en relación directa la posibilidad de ejercicio de una competencia externa con el contenido expreso de las normas internas ya vigentes que, por una parte, deben resultar directamente afectadas por las normas de los acuerdos entre Estados miembros y terceros Estados y, por otra, que se haya dado lugar a una violación suficientemente caracterizada de una norma de derecho comunitario.

Este planteamiento, establecido por el TJCE en un momento en el que ya podía conocer como se concebiría básicamente en el proyecto de tratado que incorporaba la Constitución Europea la acción exterior de la Unión, es coherente y se puede encuadrar perfectamente en la formulación del apartado 1 del art. III-225 que dispone que «la Unión podrá celebrar acuerdos con uno o varios terceros Estados u organizaciones internacionales cuando la Constitución asi lo prevea o cuando la celebración de un acuerdo sea necesaria para alcanzar, en el contexto de las políticas de la Unión, algunos de los objetivos establecidos por la Constitución, esté prevista en un acto jurídico vinculante de la Unión o afecte a un acto interno de la Unión», confirmando así el crite-

"31. que esta competencia comunitaria excluye la posibilidad de una competencia concurrente de los Estados miembros, ya que cualquier iniciativa tomada fuera del marco de las instituciones comunes es incompatible con la unidad del mercado común y con la aplicación uniforme del Derecho comunitario». 86 y 87.

20 Por ejemplo, en la recaída en el asunto C-467/98, Comisión/Reino de Dinamarca, en los apartados 85,
} 
regula específicamente el sistema de asociación con una serie de países y territorios ${ }^{23}$, de tal manera que esta acción se deberá llevar a cabo como se estipula en el texto de la Constitución Europea, sin necesidad de que su ejecución comporte la celebración de ulteriores acuerdos internacionales, sino simplemente mediante la adopción por unanimidad de reglamentos y decisiones por parte del Consejo de Ministros, tal y como dispone el art. III-191.

De esta forma, se ha llegado a la configuración de una nueva política de la Unión Europea, integrada en su sistema funcional y llevada a cabo por las instituciones de la Unión.

Aunque no se diga nada en concreto referido a la categoría de esta política de asociación de los países y territorios de ultramar, sino es que está referida a los países y territorios no europeos que mantienen relaciones especiales con Dinamarca, Francia, los Países Bajos y el Reino Unido, del contenido de la letra e) del artículo III-187 y del artículo III-190, cabría deducir que, por lo menos en las materias a que estas disposiciones se refieren, se podría considerar como una política común, con la consiguiente exclusividad de competencias para las instituciones de la Unión.

El planteamiento de este sistema de asociación , de acuerdo con el art. III-187, extiende a los citados países y territorios el régimen de la libre circulación de mercancías y de trabajadores (esta última, instaurada en el art. II-190), la participación en igualdad de condiciones en las convocatorias para la adjudicación de obras, servicios y suministros para todas las personas físicas y jurídicas que tengan la nacionalidad de los Estados miembros o de los países y territorios, el derecho de establecimiento para personas físicas y sociedades, de acuerdo con el principio de no discriminación y según «los reglamentos y decisiones europeos» que el Consejo de Ministros adopte por unanimidad siguiendo el procedimiento previsto en el art. III-191. Esta regulación de la asociación también contribuye a ampliar y reforzarla capacidad de actuación internacional de la Unión porque supone la aceptación de los referidos terceros Estados y territorios de la validez y eficacia de los actos adoptados unilateralmente por las instituciones de la Unión para el desarrollo del sistema de asociación previsto en este título de la Constitución Europea.

D) En otro orden de cosas, siguiendo una sistemática distinta y fuera ya del marco de las políticas funcionales integradas de la Unión, la cooperación para el desarrollo, que el art. III18 dispone que se llevará a cabo en el marco de los principios y objetivos de la acción exterior de la Unión, se encuentra también particularmente reforzada y concebida para ser realizada de una forma eficaz y complementaria entre la Unión y los Estados miembros. Eso si, en el marco de la coordinación y la concertación de programas, abriendo la posibilidad de emprender acciones comunes, de acuerdo con el apartado 1 del art. III-220.

Reforzada a pesar de que sus objetivos están concebidos de forma muy general y nada precisa, puesto que en el art. III-218 empieza por establecer que esta política se llevará a cabo en el marco de los principios y objetivos de la acción exterior de la Unión, considerando que su objetivo esencial será la reducción y, finalmente, la erradicación de la pobreza. Sin embargo, estos fines tan poco determinados y carentes de cualquier tipo de priorización particularizada en la Constitución ${ }^{24}$, puede ganar en coherencia al disponer el apartado 1 del art. III-219 que las medidas necesarias para ejecutar la política de cooperación para el desarrollo se establecerán mediante leyes o leyes marco europeas, confiriéndoles así, en el ámbito de la Unión, un rango normativo igual o superior a cualquier disposición adoptada por las instituciones, aunque también en el párrafo $2^{\circ}$ del apartado 2 de este mismo artículo se deje bien claro que ello no 
Es más, se propone la coordinación de unas y otras actividades a través de la Comisión Europea (artículo III-223, apartado sexto), sin perjuicio de la coordinación con las organizaciones y organismos internacionales (apartado séptimo del mismo artículo) ) ${ }^{22}$.

El art. III-223 empieza por encuadrar este tipo de actuación en el marco general de los principios y objetivos de la Unión, aunque a renglón seguido delimita el objeto de dichas acciones, dando prioridad a aportar de manera concreta asistencia, socorro y protección a las poblaciones de los terceros países víctimas de catástrofes naturales o de origen humano, para hacer frente a las necesidades humanitarias resultantes de esas situaciones.

Las decisiones de actuación se establecerán mediante leyes o leyes marco, en un ámbito muy amplio, puesto que el apartado 4 del art. III-223 dispone que la Unión podrá celebrar, tanto con terceros Estados como con organizaciones internacionales, «cualquier acuerdo adecuado para la consecución de los objetivos enunciados en el art. III-193». Así, aunque se trate de preservar la mayor coherencia posible en la acción exterior de la Unión, la amplitud de los objetivos del art. III-193 garantiza un gran margen de maniobra de la Unión en el ámbito de la ayuda humanitaria.

Finalmente el párrafo $2^{\circ}$ de este mismo apartado 4, define la consideración de competencia compartida de esta actividad al decir que «el primerpárrafo no afectará a las competencias de los Estados miembros para negociar en los organismos internacionales y celebrar acuerdos internacionales».

B) La concepción actual del sistema de cooperación económica, financiera y técnica se introduce en el Tratado de Niza. La Constitución Europea la recoge, pero estableciendo en el apartado 1 del artículo III-221 que las acciones de cooperación formuladas en la sección 2 del Título III (en el que se encuadra este artículo), y en particular en los artículos III-218 a III-220, las llevará a cabo la Unión con terceros países distintos de los países en vías de desarrollo. En este sentido, el mismo apartado 1 del art. III-221 dispone que «estas acciones serán coherentes con la politica de desarrollo de la Unión y se llevarán a cabo en el marco de los principios y objetivos de su acción exterior», disposición que refuerza el significado de la actuación de la Unión como Organización Internacional, que debe mantener el ejercicio de sus competencias en el ámbito de las normas de la Constitución, condicionando asimismo el alcance de sus actos.

Por otra parte, asegura este carácter de la acción de cooperación de la Unión al establecer «in fine» en este apartado una disposición expresamente dirigida a la regulación de una competencia compartida, al disponer que las acciones de la Unión y de los Estados miembros se completarán y reforzarán mutuamente, insistiendo de esta forma en la obligación que tienen los Estados de actuar en los ámbitos de competencias compartidas de acuerdo con los fines y objetivos de la Constitución.

C) En lo que se refiere al establecimiento de un sistema de asociación, el art.III-226 dispone de forma general que «la Unión podrá celebrar acuerdos de asociación con uno o varios terceros Estados o con organizaciones internacionales. Tales acuerdos establecerán una asociación que entrañe derechos y obligaciones recíprocos, acciones comunes y procedimientos particulares». Por su parte, la Parte III de la Constitución, en su Título IV «De la asociación de los países y territorios de ultramar», 


\section{COHERENTE Y EFICAZ DE LA UNIÓN EUROPEA.}

La indiscutible prioridad concedida por la Unión Europea en 2003 a la realización de la ampliación, ha tenido múltiples consecuencias, no sólo por la asociación inmediata de los países candidatos a la elaboración de numerosos actos comunitarios, sino también en los métodos de trabajo utilizado para la adopción de los mismos, para que pudieran participar los representantes de dichos Estados.

Asimismo se abrió un segundo círculo respecto de Bulgaria y Rumania, en el que las negociaciones con estos países progresaron notablemente, y se siguió muy atentamente la evolución de Turquía, en el sentido del respeto de los criterios políticos indisociables de la adhesión.

Por otra parte, en un tercer círculo, que está constituido por los países de los Balcanes Occidentales, su vocación de integrarse a largo plazo en la Unión Europea fue también impulsada en 2003, paralelamente a la consolidación del proceso de estabilización y asociación que caracteriza su actual relación con la Unión.

En junio de ese mismo año el Consejo Europeo de Salónica dio un gran paso en este sentido, que luego continuó en una cumbre Unión Europea - Balcanes Occidentales. Por su parte Croacia - presentó formalmente una solicitud de adhesión.

La preponderancia concedida al objetivo de la ampliación y la importancia del esfuerzo desplegado en torno a él han llevado a la consideración de muchas posibilidades de actuación estratégica en materia de cooperación y seguridad con todos aquellos países que ahora constituyen los límites inmediatos de la Unión ampliada.

Estas consideraciones han desembocado en la concepción de una Política Europea de Vecindad (en adelante PEV) como un área específica de desarrollo de competencias comunes, que además ha sido recogida de forma específica en la Parte I, Título VIII, artículo 56 de la Constitución Europea, como un objetivo de la Unión con contenido propio, referido expresamente a su entorno próximo y que dispone que «la Unión desarrollará con los Estados vecinos relaciones preferentes, con el objetivo de establecer un espacio de prosperidad y de buena vecindad basado en los valores de la Unión y caracterizado por relaciones estrechas y pacificas basadas en la cooperación», y que el propio art. 56, en su apartado 2, dispone que deberá desarrollarse de acuerdo con lo dispuesto en el art. III-227, que formula el sistema de celebración de los acuerdos internacionales.

El conjunto de acciones a las que puede dar lugar el despliegue de las competencias a las que se basan en este Título VIII, proporciona una capacidad de desarrollo específico de la acción exterior de la Unión, en torno a objetivos delimitados pero de gran amplitud, que refuerza su presencia efectiva en el ámbito internacional y sus posibilidades de actuación como sujeto de derecho internacional.

\subsubsection{LA PUESTA EN MARCHA DE LA PEV}

De esta forma, en respuesta a una carta conjunta dirigida al Consejo en agosto de 
afectará a las competencias de los Estados miembros para negociar en los organismos internacionales y celebrar acuerdos internacionales.

E) En cuanto a las relaciones entre la Unión Europea y otras organizaciones internacionales, hay que distinguir entre los supuestos de participación de la Unión en las mismas, y la cooperación con estos sujetos de derecho internacional. En el primer caso, mantiene plenamente su vigor el análisis de la profesora Paz Andrés y Sáenz de Santamaría cuando consideraba que esta cuestión la CE se enfrentaba a un doble problema: «Desde la perspectiva interna, la capacidad de la Comunidad para actuar en otras organizaciones está condicionada... a la existencia de competencia comunitaria y a la división de poderes entre aquella y los Estados miembros; desde la perspectiva externa, la presencia de la CE en otra organización internacional está condicionada por el tratado constitutivo de esta. Desde esta óptica, la necesidad de acomodarse al derecho institucional de cada organización supone que no basta con que se cumplan las condiciones impuestas por el derecho comunitario e incluso puede ocurrir que aunque la CE tenga capacidad conforme a su ordenamiento, no pueda obtener el estatuto que más le convenga por impedirselo las normas de la organización. En este caso, la solución pasaría por una enmienda del tratado constitutivo de tal organización, lo que depende de la voluntad politica de sus miembros, que en ocasiones puede no existir». ${ }^{25}$

Respecto del supuesto de una cooperación con organizaciones internacionales en sectores de actividad de interés común, el apartado 3 del art. III-220 incluye específicamente el compromiso de cooperar con las organizaciones internacionales competentes, compromiso sobre el que insiste en el apartado 3 del art. II-221, que añade, también de forma general, que «las modalidades de cooperación de la Unión podrán ser objeto de acuerdos entre ésta y las terceras partes interesadas, los cuales serán negociados y celebrados de conformidad con el art. III-227», es decir, en el marco de la competencia autónoma de la Unión para celebrar acuerdos internacionales. Ahora bien, en el Capítulo VII del Título V de la Parte Tercera (arts. III-229 y III-230), se precisa la necesidad de cooperar con las Naciones Unidas, el Consejo de Europa, la Organización para la Seguridad y la Cooperación en Europa y la Organización de Cooperación y Desarrollo Económico, con lo que se establece un sistema de prioridades en cuanto a los objetivos de cooperación y se polariza el sistema de relaciones con organizaciones internacionales al dar expresamente relevancia al mantenido con las citadas en el apartado 1 del art. III-229, claramente diferenciadas de las demás, con las que en el apartado 2 de dicho artículo se dispone que mantendrá «relaciones apropiadas».

F) Por su parte, en la Constitución se establece un régimen cualificado de cooperación sin precedentes en ninguno de los anteriores tratados constitutivos para regular las relaciones de vecindad. El mecanismo para llevar a cabo este sistema de cooperación se establece en el Título VIII de la Parte I «De la Unión y su entorno Próximo», cuyo art. 56 dispone en su apartado 1 que «la Unión desarrollará con los Estados vecinos relaciones preferentes, con el objeto de establecer un espacio de prosperidad y de buena vecindad basado en los valores de la Unión y caracterizado por relaciones estrechas y pacíficas basadas en la cooperación».

\subsection{UNA POLÍTICA DE VECINDAD QUE POSIBILITE UNA ACCIÓN}

24 En este sentido, cabe señalar la diferencia con la política de asociación de los países y territorios de ultramar. Es verdad que el nivel de relación y de interacción con dichos países y territorios es muy diferente, pero 
un compromiso recíproco a favor de valores comunes, situándose en particular en los ámbitos del Estado de derecho, del buen gobierno, del respeto de los derechos humanos y de las libertades fundamentales (concretamente de los derechos de las minorías), de la promoción de todos los aspectos que afecten a la práctica de una vecindad positiva y de los principios de la economía de mercado y del desarrollo sostenido.

En este sentido se entiende que se deberá exigir un régimen de igualdad respecto de los compromisos aceptados por los países vecinos en cuanto se refiere a los elementos esenciales de la acción exterior de la UE, en particular en la lucha contra el terrorismo y la proliferación de armas de destrucción masiva, así como al respeto del Derecho Internacional y la realización de esfuerzos en el ámbito del arreglo pacífico de las controversias.

Los planes de acción se establecerán de acuerdo con un conjunto de principios comunes a todos los Estados participantes pero luego serán individualizados en función de la situación de las relaciones con cada Estado en concreto, sus necesidades y capacidades así como los intereses recíprocos con la Unión. El alcance de las relaciones de la UE con sus vecinos estará en proporción con la medida en que dichos valores sean realmente compartidos.

En este sentido, se considera que Rusia es un Estado fundamental en la configuración inmediata de la PEV. Rusia y la UE han decidido desarrollar una asociación estratégica mediante la creación de cuatro espacios comunes, que fueron definidos en la cumbre de San Petersburgo en mayo de 2003.

Por otra parte, Bielorrusia y la Unión estarán en situación de establecer vínculos contractuales específicos en el momento en que Bielorrusia ponga en práctica una forma de gobierno democrático que surja de unas elecciones libres y organizadas de acuerdo con las garantías y procedimientos del Estado de Derecho. Así se podrá beneficiar totalmente de las ventajas ofrecidas por la PEV. Mientras tanto, la UE estudiará que medios puede adoptar para reforzar su ayuda a la sociedad civil para que progrese en su desarrollo hacia una estructuración que le permita el acceso a dicha forma de estado en las mejores condiciones posibles.

En el flanco sur, la UE espera que Libia se integre en la ronda de negociaciones con los Estados mediterráneos constituida por el denominado «proceso de Barcelona», lo que debía tener lugar de forma automática en el mismo momento en que dicho país acepte y reconozca los resultados ya obtenidos por las demás partes en el desarrollo de ese proceso y haya llegado a un acuerdo sobre el arreglo pacífico de todas las controversias bilaterales pendientes de solución. Esto abriría la vía a una normalización de las relaciones y permitiría a Libia beneficiarse de la PEV.

De esta forma, se puede considerar en términos generales que la PEV contribuirá a la consolidación de todas las formas ya existentes de cooperación regional y subregional y

valga como ejemplo de la distinta intención que se expresa cuando un plan de acción está bien articulado en todos sus elementos y cuando se establece de forma abstracta y totalmente generalizada porque no existe una estrategia definida ni un posicionamiento definitivo frente a buen número de los Estados terceros. Por eso se busca el margen de maniobra y la libertad de apreciación que proporcionan los planteamientos generales, que después se podrán regular de una forma u otra según convenga en cada caso.

25 Andrés y Sáenz de Santamaría, P., op. cit, p. 125 
2002 por Solana y Patten en marzo de 2003, la Comisión presentaba una comunicación titulada «Europa ampliada - Vecindad: Un nuevo marco para las relaciones con nuestros vecinos del Este y del Sur» ${ }^{26}$.

En junio de 2003, el Consejo acogía esta comunicación y consideraba que constituía una base adecuada para desarrollar una nueva serie de políticas respecto de los países vecinos a la Unión ampliada, procedía a definir los objetivos y principios generales e identificar las medidas que podían servir para iniciar esta nueva política común. Tras esta actuación, el Consejo Europeo reunido en Salónica ese mismo mes, ratificó las conclusiones del Consejo y daba luz verde para que el Consejo y la Comisión empezaran sus trabajos de estructuración de los diferentes elementos de estas políticas.

Inmediatamente después, en julio de 2003, la Comisión presentaba otra comunicación, titulada «Poner las bases de un nuevo instrumento de vecindad» ${ }^{27}$ y creaba un grupo de trabajo llamado «Europa ampliada». En octubre el Consejo invitaba a la Comisión a presentar propuestas concretas para establecer planes de acción a principios de 2004, de forma que pudiera elaborarse en junio de este año un primer proyecto integrado sobre las acciones a efectuar en el conjunto de los países que se consideran dentro del área de la PEV.

Sobre esta base la Comisión procedía a efectuar un análisis detallado de los elementos susceptibles de ser integrados en esta iniciativa, tanto en cuanto se refería al contenido como al procedimiento para llevarlos a cabo. Así, en octubre de 2003 y en febrero de 2004, ha podido presentar al Consejo dos informes verbales respecto del estado de los trabajos y se ha podido llegar a un examen detenido de los mismos en el COREPER de los proyectos iniciales de actuación respecto de un cierto número de países del Este y del Mediterráneo en el contexto de la PEV, vinculados a acciones de cooperación política y a la PESC.

En este sentido, la Comisión llevó a cabo conversaciones exploratorias con países como Israel, Jordania, Moldavia, Marruecos, Autoridad Palestina, Túnez y Ucrania, con los que ya existen acuerdos de cooperación o de asociación. Las conversaciones realizadas han confirmado el interés que tales países tienen en la PEV y han ayudado a precisar que prioridades hay que establecer en los proyectos de actuación respecto de cada país en cuestión.

Desde que se concibió la PEV, la Unión ha insistido en que considera que su principal objetivo consiste en compartir con los países vecinos los beneficios de la ampliación, como instrumento adecuado para reforzar la estabilidad, la seguridad y el progreso del conjunto de la población de los Estados interesados. La PEV debe tender a evitar nuevos desequilibrios entre la UE ampliada y sus vecinos y ofrecerles la posibilidad de participar en diversas actividades de la UE en el contexto de una cooperación política, de seguridad, económica y cultural reforzada.

El sistema que se propone consiste en definir, de acuerdo con los Estados interesados, un conjunto de prioridades cuya realización les permita aproximarse a la UE, Estas prioridades deberán integrarse en los proyectos de actuación adoptados conjuntamente, que comprenderán un cierto número de objetivos claves que requieran una acción específica (diálogo político y reforma, comercio y medidas que hagan posible una participación progresiva en el mercado interior de los Estados en cuestión, justicia y asuntos internos, energía, transportes, sociedad de la información, medio ambiente, investigación e innovación, política social y contacto entre comunidades).

Las relaciones privilegiadas con los vecinos en el marco de PEV deberá apoyarse en 
común (lo que incluiría especialmente el medio ambiente y la energía); un espacio común de libertad, de seguridad y de justicia; un espacio de cooperación en el ámbito de la seguridad exterior, así como un espacio de investigación y de educación. En este sentido, el diálogo con Rusia en el ámbito de la energía constituiría un elemento clave de la relación global.

Así pues, el primer objetivo de la PEV consiste en conferir una nueva dimensión a la cooperación con los vecinos de la UE después de la ampliación. La experiencia acumulada en la acción de apoyo concedido al proceso de transición política y económica, así como al desarrollo económico y a la modernización de los nuevos Estados miembros y a los países candidatos, constituye una referencia que puede trasladarse a las relaciones con los Estados vecinos.

Por otra parte, la PEV debe reforzar la contribución de la UE a la promoción del arreglo pacífico de controversias de carácter regional. De esta forma estaría actuando también en su propio beneficio porque este tipo de acción le vendría bien para la consecución de sus objetivos en el ámbito de la justicia y de los asuntos internos, en particular en todo aquello que se refiere a la lucha contra el crimen organizado y la corrupción, el blanqueo de capitales y todas las formas de tráficos ilegales, así como en lo concerniente a todas las cuestiones vinculadas con la inmigración.

La PEV se dirige a los Estados vecinos de la Unión Europea y, en particular, a aquellos que se han aproximado especialmente en sus relaciones a causa de la ampliación.

a) En el continente europeo se aplicará a Rusia, Ucrania, Bielorusia y Moldavia. En este sector la UE y Rusia han decidido desarrollar su asociación estratégica en los cuatro sectores delimitados en la reunión de San Petersburgo de $2003^{29}$.

b) En la región mediterránea se aplica a todos los Estados que, sin ser miembros de la UE, participaron en el Proceso de Barcelona (Argelia, Egipto, Israel, Jordania, Líbano, Libia, Marruecos, Siria, Túnez y Autoridad palestina), con la excepción de Turquía, cuyas relaciones con la UE se insertan en el contexto del procedimiento previo a la adhesión.

d) De igual manera, la Comisión recomienda la inclusión de Armenia, Azerbaijan y Georgia en el ámbito de la PEV (finalmente han sido incluidos en junio de 2004).

Se han abierto debates exploratorios con el objetivo de identificar los elementos que se podrían integrar en eventuales planes de acción con Estados vecinos respecto de los cuales están en vigor acuerdos de cooperación o de asociación. En este sentido también se considera la adopción de planes de acción en el segundo semestre de 2004 respecto de otros países mediterráneos que también hayan ratificado acuerdos de asociación, como Egipto y el Líbano, así como para otros Estados de esta región, en el momento en que sus relaciones con la UE alcancen el mismo nivel. Estos acuerdos prevén el desarrollo de la cooperación y de la integración económica en un gran número de sectores, atendiendo a las prioridades establecidas en la PEV.

Como conclusión, se puede considerar que se ha acertado a delimitar un ámbito de actuación común en el que se pueden desplegar todas las posibilidades de ejercicio de la 
dará lugar a la configuración de un marco bien determinado para un progresivo desarrollo futuro. Reforzará la estabilidad y la seguridad y facilitará el arreglo pacífico de los conflictos existentes en la actualidad a todo lo largo de las fronteras de la Unión ampliada.

Mediante el establecimiento de un desarrollo continuo de diversas formas de cooperación transfronteriza, integrando en un mismo sistema de acciones concertadas a autoridades locales y regionales y a actores no gubernamentales, la UE y los Estados interesados podrán actuar de común acuerdo, de forma que las regiones fronterizas se beneficien de la ampliación de la UE.

En las regiones meridionales, la PEV tiene que contribuir especialmente al desarrollo del proceso de cooperación euro - mediterráneo (proceso de Barcelona), sobre todo promoviendo interconexiones y redes de infraestructuras, particularmente en el ámbito de la energía (oleoductos, gaseoductos y tendidos de redes de alta tensión) y en la puesta a punto de nuevas formas de cooperación entre los Estados vecinos. La PEV contribuiría así al desarrollo del proceso de integración regional sobre la base de los resultados conseguidos en el marco de la asociación euro - mediterránea en el ámbito de las transacciones comerciales e incrementaría los esfuerzos para realizar los objetivos de la estrategia europea de seguridad en la región mediterránea y en el Oriente Medio.

En síntesis, se puede considerar que el contenido nuclear de la PEV deberá estar constituido por un sistema de relación cada vez más estrecho y que vaya más allá del concepto tradicional de cooperación, implicando al conjunto de Estados que rodean a la UE en un nivel de integración económica y política importante, que se comprometan y compartan plenamente sus valores y sus objetivos fundamentales, cuya primera fase, de tres a cinco años, consistiría en definir con precisión este contenido, para pasar en la siguiente a la negociación directa por parte de la UE de acuerdos de vecindad, que irían reemplazando a los tratados bilaterales existentes, respetando las prioridades establecidas en la concepción de conjunto fijado para esta acción común. Aspectos que se refuerzan de una manera muy concreta en la propuesta de Reglamento del Parlamento Europeo y del consejo presentada por la Comisión el 29 de octubre de $2004^{28}$, en cuya exposición de motivos se señala. En relación con los objetivos y principios del futuro Reglamento y de la PEV, que la creación de una zona de buena vecindad requiere recursos destinados a promover la cooperación transfronteriza entre los países interesados y los Estados miembros para promover el desarrollo regional integrado en el ámbito de las regiones limítrofes afectadas, procediendo a disponer una formula para que la asistencia prevista llegue de igual manera y con los mismos efectos a todos los territotios comprendidos en esa área, de manera que se de lugar a un desarrollo homogéneo y equilibrado.

\subsubsection{PRINCIPIOS, ALCANCE Y ÁMBITO DE APLICACIÓN}

La importancia de una PEV se pone de manifiesto en la configuración de una estrategia europea de seguridad, cuyas líneas generales las adoptó el Consejo Europeo de diciembre de 2003 al declarar que corresponde a la UE realizar una contribución específica a la estabilidad y al buen gobierno en nuestra más inmediata vecindad, así como promover un conjunto de países bien gobernados al este de la UE, sobre todo en el entorno mediterráneo, con los que podamos mantener unas relaciones muy estrechas fundadas en la cooperación. Estas relaciones se extenderían a la consecución de un espacio económico 
JOSÉ A. GIRÓN LARRUCEA 
subjetividad internacional de la Unión Europea. Constituyendo un sector de actividad de la misma naturaleza que la PESC, cuenta sin embargo con dos factores a su favor que permitirán, sin duda, un desarrollo continuo y efectivo que pronto le podrán dar un contenido sustantivo como política común:

El hecho de su concreción, de haber sido concebida para actuar en un ámbito específico para la consecución de unos objetivos bien determinados es la mejor garantía de un desarrollo eficaz de las competencias que lleven a la consecución de dichos objetivos.

También es positiva la circunstancia de haberse creado en directa concertación con los países y territorios que se pueden beneficiar y que desean una acción común de la unión Europea que refuerce y confiera estabilidad a sus relaciones con la Unión Europea. Cada uno sabe en que medida y en que materias le interesa colaborar en función de sus propios intereses, lo mismo que los Estados de la Unión, que saben hasta que punto y a través de que procedimientos se van a llevar a cabo las acciones en cuyo desarrollo tienen que participar desde su condición de Estados miembros. 
JOSÉ A. GIRÓN LARRUCEA

29 Israel, Jordania, Moldavia, Marruecos, Autoridad palestina, Túnez y Ucrania. 
